A Remarkable Meteor on November 24.

I wAS much interested in seeing Dr. Rambaut's letter describing a brilliant meteor seen at Oxford on the evening of November 24. I was travelling along the London to Oxford road at the time, and when passing through Stokenchurch (seventeen miles from Oxford) was suddenly aware of a pale green light of sufficient intensity to be quite noticeable even when looking down at the road. On looking up I saw the meteor just as it disappeared. It presented the appearance of a luminous green ball of about one-quarter the sun's diameter, though this can only be regarded as quite an approximate estimate. My first impression was that the phenomenon was an unusual type of meteor, but on account of the brilliant green colour I immediately afterwards came to the conclusion that it must have been a rocket, and therefore did not unfortunately note the exact time or careful particulars as to the position. I should estimate that the meteor lay about N.N.E. when I saw it, but that the altitude was somewhat greater than the $17^{\circ}$ given by Dr. Rambaut. The agreement in time and place was, however, sufficiently close to leave no doubt that it must have been the same phenomenon. The intensity of the illumination may be judged from the fact that the light was quite noticeable to one not looking up towards the sky at the time. Meteorological Office, South Farnborough Branch,
December $x$.

I REGRET to have to have to point out a mistake in my letter printed in NaTuRE for November 27 (p. 372). The altitude of the meteor should have been given as $27^{\circ}$, not $17^{\circ}$ as there stated.

As the error appears in my copy, I fear I must bear all blame for it.

Radcliffe Observatory, Oxford, December I.

\section{THE BRITISH RADIUM STANDARD.}

$A \mathrm{~N}$ account of the preparation and testing of $A$ an international radium standard was given in the issue of this journal for April 4, rgr2 (vol. Ixxxix., p. II5). It will be remembered that a radium standard containing $2 \mathrm{I}^{\circ} 99$ milligrams of pure radium chloride was prepared by Mme. Curie for the International Committee. At a meeting in Paris the standard of Mme. Curie was compared with another independent standard prepared in Vienna by Professor Hönigschmidt, and the two were found to agree well within the limits of accuracy of measurements by the $\gamma$ ray method. The preparation of Mme. Curie was accepted by the Committee as the International Standard, and was deposited in the Bureau du Poids et Mesures at Sevres, near Paris. At the same time it was arranged that the Vienna preparation should be retained in Vienna as a secondary standard. Arrangements were made to allow Governments to obtain duplicates of the international standard. For this purpose the Austrian Government generously offered to provide the radium required at a considerable reduction in price. It was arranged that duplicate standards should be prepared and tested in Vienna in terms of their secondary standard, and then sent on to Paris to be tested again in terms of the international standard. In all six duplicate standards have NO. $23 \mathrm{OI}$, VOL. 92$]$ now been prepared for different Governments, and the independent standardisations of the radium content in Vienna and Paris has been found to be in remarkably good agreement. The comparisons of the quantities of radium is made by means of the penetrating $\gamma$ rays, and it is a striking testimony to the accuracy of this method that the independent measurements have agreed so closely, although widely differing experimental arrangements have been employed in the two places.

It will be remembered that Dr. Beilby, F.R.S., very generously defrayed to Mme. Curie the cost of the radium forming the international standard, and thus relieved the International Committee of the necessity of collecting special funds for this purpose. Immediately after the fixing of the international standard, arrangements were made in this country to obtain a duplicate standard to be placed in charge of the National Physical Laboratory at Teddington. Dr. Beilby again stepped in in a very generous manner and agreed to defray the expense of acquiring the British radium standard, which was delivered to the National Physical Laboratory a few months ago. The British radium standard does not differ much in radium content from the international standard, containing about 20 milligrams of pure radium chloride.

A circular has now been issued by the National Physical Laboratory, stating that they are prepared to standardise preparations of radium and mesothorium in terms of the international standard, and a detailed list of testing charges has been issued. In the beginning, the Laboratory has very wisely confined itself to undertaking the standardisation of strong preparations of radium and mesothorium only. The comparison with the British standard will be made by $\gamma$ ray methods. Tests on radio-active minerals, radioactive waters and other materials of weak activity, will not be undertaken at the moment, though, no doubt, arrangements will be made as the new radio-active department progresses to undertake some work of this character in the future. The Laboratory sends out a certificate that the active material under examination shows a $\gamma$ ray activity equivalent to a certain weight of metallic radium, but no guarantee is given of whether the activity is due to radium itself, for it is well known that it is not easy to distinguish without special tests between preparations of radium and mesothorium. Preparations of the latter are standardised by expressing their $\gamma$ ray activity at the time of testing in terms of a definite weight of metallic radium in radio-active equilibrium. Both the Reichsanstalt and the National Physical Laboratory express the activity of their preparations in terms of metallic radium, and not in terms of bromide or chloride. This appears to me a very wise step, for it is obviously more definite and scientific to express the results in this form. It is also very desirable that all radium should be bought and sold in terms of metallic radium, thus avoiding the uncertainty that some- 
times arises as to whether the preparation is being sold as anhydrous radium bromide or radium bromide with its water of crystallisation.

The radio-active department in the Reichsanstalt has now been in operation for more than a year, under the charge of Dr. Geiger, whose radio-active researches in the University of Manchester are well known. The creation of this department has been found to fill a much-needed want, and it is not too much to say that practically all the radium and mesothorium that is bought and sold in Germany requires to-day the certificate of the Reichsanstalt. The number of standardisations required have increased very rapidly, and several assistants have been added to the department in charge of this work alone. There can be no doubt that the institution of a radio-active department in the National Physical Laboratory will prove of great service to this country, not only for scientific, but also for commercial purposes. It is well known that the buying and selling of radium in the past has been a very uncertain and risky procedure, for in most cases the radium content has not been expressed in terms of any authorised standard. This difficulty is removed by the present arrangement, and we should strongly recommend that those who wish to buy radium or mesothorium, whether for scientific or for medical purposes, should do so conditional on the certificate of standardisation from the National Physical Laboratory.

It is understood that the work of testing and standardisation will be under the supervision of Dr. W. G. C. Kaye, of the National Physical Laboratory, whose pioneer work on the production and distribution of X-rays is well known to all physicists. The ability and skill in measurements which he has shown both in his work in the Cavendish Laboratory and in the National Physical Laboratory, afford the best of guarantees that the work of the new department will be carried out in a thoroughly satisfactory manner.

E. Rutherford.

\section{SIR ROBERT BALL, F.R.S.}

ROBERT STAWELL BALL was born in Dublin on July $\mathrm{I}$, I840, the eldest son of Dr. Robert Ball, director of the Natural History Museum in the University of Dublin and secretary of the Queen's University in Ireland. After attending school at Abbott's Grange, Chester, he entered Trinity College, Dublin, in $1857 . \mathrm{He}$ became a mathematical scholar in I860, Lloyd exhibitioner the same year, and graduated in I86I as gold medallist in mathematics, first gold medallist in experimental and natural sciences and University student in mathematics. Towards the end of $x_{86}$ he went to Parsonstown as tutor to the three younger sons of the third Earl of Rosse and observer with the great sixfoot and three-foot telescopes. When Ball began to use the six-foot reflector in February, 1866 , nearly all the larger and more interesting nebulæ had been frequently observed and carefully drawn, and he therefore chiefly devoted himself to work with the micrometer, a difficult task, since the telescope at that time had not yet been provided with a clock motion. He was the first observer with the instrument who corrected the measured position angles for the error due to the telescope not being equatorially mounted, but supported at the lower end on a universal joint. His observations were included in the "Observations of Nebulæ, I848-78," published by the late Lord Rosse in $1879-80$.

In the autumn of 1867 , shortly before the death of the maker of the great telescope, Ball was appointed professor of applied mathematics and mechanism at the newly established Royal College of Science for Ireland, in Dublin. He was singularly well fitted for this post, as he was not only an excellent mathematician and had the power of elucidating even abstruse subjects in simple and clear language, but also possessed great skill in experimental work. In addition to his regular class work, he also sometimes gave evening lectures on mechanics in a more elementary form, and in $187 \mathrm{I}$ he published his first popular book, "Experimental Mechanics," which was very well received and showed his great aptitude both as a popular lecturer and as a writer. It led to his being much sought after as a lecturer; and as lectures on mechanics required a large amount of apparatus, he preferred to lecture on popular astronomy, and by degrees he became the most successful lecturer on this subject, not only in this country, but in after years also in America.

In January, 1870 , Ball read a paper before the Royal Irish Academy on the small oscillations of a rigid body about a fixed point under the action of any forces. Out of this investigation grew the long series of memoirs which he published on the theory of screws in the course of the next thirty-four years, nearly all in the Trans. Roy. Irish Academy. This remarkable extension of theoretical dynamics, perhaps the most important contribution to that science since the introduction of couples by Poinsot, combines Poinsot's force and couple into the single conception of a wrench on a screw, the latter being regarded merely as "a directed straight line with an associated linear magnitude called the pitch." The capabilities of the theory were gradually shown to be very great, as all the results of modern algebra and geometry appear to be applicable to it. Ball published a separate book on the subject in 1876 , and in I889 Dr. Gravelius wrote a text-book in German, founded on Ball's first eight memoirs. Finally, Ball's great "Treatise on the Theory of Screws" appeared at Cambridge in 1900 , but even after that date several succeeding memoirs showed that the author of the theory continued to devote his mind to its extension.

The growing fame of Ball as a mathematician and the warm interest he was kirown to take in astronomy naturally led the Board of Trinity College to appoint him to the Andrews professorship of astronomy in the University of Dublin, 